\title{
Fragmentation of Students' Thinking Structure in Constructing the Concept of Linear Inequality of Two Variables
}

\author{
Mutia Sari Widyaningrum ${ }^{1 *}$ Budi Usodo $^{2}$ Hasih Pratiwi $^{3}$ \\ ${ }^{1}$ Postgraduate School of Mathematics Education, Faculty of Teacher Training and Education, Universitas \\ Sebelas Maret Surakarta, Indonesia. \\ ${ }^{2,3}$ Faculty of Teacher Training and Education Universitas Sebelas Maret Surakarta, Indonesia. \\ *Corresponding author. Email: mutiasw@student.uns.ac.id
}

\begin{abstract}
Learning mathematics has a clear, ordered and complete structure or pattern of thinking. Fragmentation of the thinking structure occurs at a time which is a factor inhibiting students' thinking processes to construct the material concepts they get and in solving mathematical problems. This study aims to analyze the occurrence of fragmentation of thinking structures by looking at students' errors in solving problem-solving abilities on the material of linear inequalities of two variables. This type of research is qualitative research. A search was conducted on the occurrence of errors in the selected research subjects by carrying out tests with the think aloud method and task-based in-depth interviews in order to obtain data on students who experienced fragmentation of thinking structures on the material of two-variable linear inequalities. The results showed that there was fragmentation of the thinking structure in students' minds, especially in constructing concepts and reviewing the results of solving these problems. Each student seems to have fragmentation of different thinking structures according to the level of understanding that students have. Students are not able to use mathematics according to the actual concept of inequality and the occurrence of fragmentation of thinking structures that hinders students' thinking processes.
\end{abstract}

Keywords: Concept construction, Fragmentation of thinking structure, Linear inequalities of two variables, Mathematical problem solving.

\section{INTRODUCTION}

The process of thinking happens in every human mind as a God's creature who can think about the ability in him. Humans are able to develop potential in them to always proceed to improve the quality of life in facing challenges in this era of disruption. Intelligence thinks every person varies according to the many experiences that have been experienced in his life. But it is found in some cases the human mind experiences inauguration and incompleteness in processing a mind. The fragmentation of the thinking structure is a phenomenon of information-oninformation storage in an inefficient brain so that it hinders the process of construction and solving mathematical problems [1]. Fragmentation can inhibit the learning process of students to carry out concepts on further material. Fragmentation can be in the form of pseudo construction (pseudo construction), incomplete structure (construction hole), separate structure and the structure of the random (not surly) [2]. While [3] states that the process of thinking is a process that starts by receiving data, processing and storing it in memory which is then taken back from memory when needed for further processing ". Because the thought process in learning mathematics is a mental activity in the minds of students, Herbert [4] states that to find out how the student thinking process can be observed through the process of doing the test and written results in sequence.

Thinking is a high-level cognitive activity. The solution to solving the mathematical problems of students is the ability to solve a math problem in a structured math through several or stages. The problem in mathematics is someone's solution, so 
students need to reason, it feels like to predict, look for a simple formulation and prove it.

In constructivism theory, the learning process is not only passively absorbing information from books or teachers, but teachers should transfer information to students to be able to construct concepts and ideas that students already have. The teacher's role is to involve students actively thinking to create, develop and use the ideas they already have into new ideas. [5] Said that in the educational process at school, it is said that learning has occurred, if the teacher has invited students to think. Conversely, if the teacher in the class has not conditioned students to think, it cannot be said that the learning process has occurred.

[6] Says that mathematics is concerned with ideas, structures and their relationships which are arranged in a logical order. So, mathematics is concerned with abstract concepts that are developed based on logical reasons to prove a statement, true or false. According to Bruner, learning mathematics is learning about mathematical concepts and structures contained in the material being studied and looking for relationships between mathematical concepts and structures [7], [8] suggests that in order to learn a new mathematical material, a person's past learning experiences will affect the mathematics learning process, one must first master the previous material because of the continuity of the material. Construction of mathematical concepts is an active activity carried out to obtain or build a concept in mathematics. Therefore, continuity in learning mathematics is needed in order to study mathematics material in a complete and interconnected manner between the previously studied materials.

In actual conditions during the learning process, students are accustomed to memorizing definitions, theorems and mathematical formulas, and lack of development of other abilities including problem solving abilities. As stated by the opinion of Suwasti [9], learning mathematics in schools has not fully contributed to students developing problem solving. The process of learning mathematics is still understood as the result of only cognitive activities, namely giving formulas and doing practice questions (practices in applying the formulas taught). The tendency of students to only focus on memorizing formulas in solving problems. They think that only by memorizing formulas can find solutions to problems. However, this may not necessarily be realized.

There are a number of things you can do to find ways to solve math problems that are easier and more fun and that you can remember the concepts in the long run. In the linear inequalities of two variables, students are required to understand various forms of questions and how to solve them according to the thinking structure that occurs in students. The material of the linear inequalities of two variables has several characteristics including the use of hyphens less than or more than. In addition, there are inequality conditions that must be considered. The linear inequality of two variables is an open sentence in mathematics in which there are two variables. Each of the variables in the linear inequality of these two variables has the degree of one and is associated with the sign of the inequality. The signs of the inequality are $>,<$, and. For that the keyword of the inequality is less than or more than.

According to [10] states that student errors in solving a math problem can occur because of the fragmentation of the thinking structure. Errors in mathematics are deviations from the correct solution of a problem, both conceptually and in solving procedures [11]. Students' mathematical thinking skills can be developed and optimized through problem solving in mathematics learning. According to Polya [12] in problem solving there are four steps that must be taken, namely: (1) understanding the problem, (2) planning a solution, (3) solving the problem according to the second step plan, (4) reexamining the results obtained (looking back). In solving mathematical problems, students not only develop low-order thinking skills but more importantly develop high-order thinking skills. The ability to think mathematics is a dynamic process that demands the birth of a variety of complex ideas so that there is an increase in understanding [13].

[14] Revealed that pseudo construction is a process of forming mathematical concepts "as if" in accordance with scientific concepts after being explored more deeply, they are not in accordance with the concept. Construction hole is the process of forming mathematical concepts that are not perfect in the formation of concepts, there are parts of concepts that are not constructed. Logical thinking error is the process of forming mathematical concepts through logical thinking or reasoning but there are deviations in the use of logical rules. As in the research conducted by Muslim, if one indicator of understanding the concept is not owned by students, it is very possible for students to experience misconceptions in understanding the concept of exponential equation material. Misconceptions will certainly result in student errors in solving mathematical problems related to exponential equations [15].

According to [16] mathematics is formed as a result of human thinking related to the idea of process 
and reasoning. Furthermore, [17] suggests that mathematics is a symbolic language that expresses ideas, structures, or logical relationships including abstract concepts making it easier for humans to think. In line with this understanding, Hudoyo says that mathematics is concerned with ideas, structures and their relationships which are arranged in a logical order. So, mathematics is concerned with abstract concepts that are developed based on logical reasons to prove a statement, true or false.

Subanji mentions that there are four kinds of fragmentation of thinking structures, namely (1) Pseudo Construction (Pseudo Construction) Subanji explains that student errors can take the form of Pseudo thinking, namely Pseudo right and Pseudo wrong. Pseudo-true occurs when students get the right answer but actually their reasoning is wrong. While Pseudo wrong occurs when the student's answer is wrong, but in fact the student is able to reason correctly. (2) Construction Hole, namely the student's thinking structure that is formed in the construction process is not intact, does not appear or disappears. The way students think spontaneously, does not pay attention to the conditions used to solve problems related to linear inequalities of two variables. Concepts that result in the concept not being fully formed. (3) Randomized structure: Fragmentation of the randomized structure occurs due to the learning process that does not pay attention to the order of prerequisites. With these logical thinking errors, there are schemes in the construction of incomplete problem solving. This fragmentation occurs during the construction process, the concepts formed are in a randomized order. (4) Separate structure this fragmentation occurs when the construction processes, the concepts are formed separately so that no link is found between the existing structures and the link between one concept and another is not visible. Fragmentation of separate structures occurs because of the process of rote learning procedures and using those procedures to solve mathematical problems.

Before conducting the research, the researcher conducted a preliminary research survey by giving easier test questions to students in one class to explore the students' initial abilities in understanding problem solving problems. As a result, the researchers found that some students still experienced errors in working on the questions, it was seen that there was fragmentation of thinking structures, especially in the construction of concepts built by students. There are students who experience pseudo-thinking processes, construction holes occur in the construction of concepts and some errors caused by incomplete and intact thinking structures.
From the explanation that has been explained, research will be carried out to determine the occurrence of fragmentation of thinking structures experienced by students which causes discrepancies and errors in mathematical concepts that occur in students' minds. One mathematical concept with another to solve mathematical problems.

\section{METHOD}

This research was conducted in class XI SMA. The research subjects selected are students who have studied the material on linear inequalities of two variables, on the grounds that the material is still stored in their memory and will try to be recalled in their memory. Sampling technique using purposive sampling method. In this study, three subjects were selected. naming for subject 1 is named S1, subject 2 is named $\mathbf{S} 2$, and subject 3 is named $\mathrm{S} 3$. The research subjects were chosen by considering the fragmentation of the thinking structure carried out by students to construct concepts and their impact when solving mathematical problems. This type of research is qualitative research. Research that intends to understand the phenomenon of what is experienced by research subjects such as behavior, perception, motivation, action, etc., holistically and by way of description in the form of words and language [18]. This study describes the structural fragmentation that occurs in constructing the material concept of a linear inequality of two variables. The main data sources in qualitative research used are in the form of words and actions of behavioral subjects obtained from in-depth interviews with research subjects. The validity of the data used in this study using triangulation techniques. The technique used to ensure the validity of the data, compare and check back the degree of trustworthiness of information obtained through different times and tools in qualitative research, is carried out by comparing the truth of information obtained from various sources.

The data collection technique used is the test with think aloud method and the interview method. The instrument in this study consisted of the main instrument, namely the researcher and the supporting instrument, namely a mathematical problem solving test for linear inequalities of two variables and interview guidelines. The test instrument has two problem-solving questions in the form of description questions. The data analyzed were the results of the two-variable linear inequality problem solving test, think aloud transcription and interview transcription on students' answers. Researchers use think aloud because it is one of the methods of collecting data 
obtained through pronunciation. Everything that the chosen research subject thinks relates to the given test. The results of this think aloud method of data collection activities aim to find out the knowledge that students have which can be observed when they do the tests given through what they think and say. In addition, from the think aloud method it will be found that there is fragmentation that occurs in students' minds. Carrying out task-based in-depth interviews using supporting questions where the implementation is more free and aims to dig deeper information on the research subject. Interviews were conducted on research subjects aimed at clarifying, exploring problems or clarifying what was stated by research subjects and to find out the structure of students' thinking in constructing the material related to linear inequalities of two variables.

The ongoing global Covid-19 pandemic has forced all schools to conduct online distance learning so that researchers have limitations in freely choosing research subjects that are in accordance with research objectives. The researcher asks the teacher for help and coordinates to determine students who are able to communicate and have good math skills so that the research can run. The teacher helped the researcher contact the students and their parents for permission. Parents of students who have given permission and students who are willing to come to school by carrying out according to the health protocol rules that apply at school such as always wearing masks, keeping a safe distance and washing hands. Selected students will be given assignments and asked to solve questions from the researcher using the think aloud method and then conduct in-depth interviews.

\section{RESULT AND DISCUSSION}

The results obtained in this study will discuss errors and fragmentation of thinking structures that occur and their possible causes in the linear inequalities of two variables in class XI high school students. The data obtained from the results of the answers to the linear inequalities of two variables and from interviews with students after working on the questions given. After conducting interviews and tracing the causes of errors that occurred, an overview of the fragmentation of the thinking structure experienced by students was obtained. The following (Figure 1) is the flow of the thinking process according to the correct thinking structure according to the steps that can be used to solve mathematical problem solving problems.

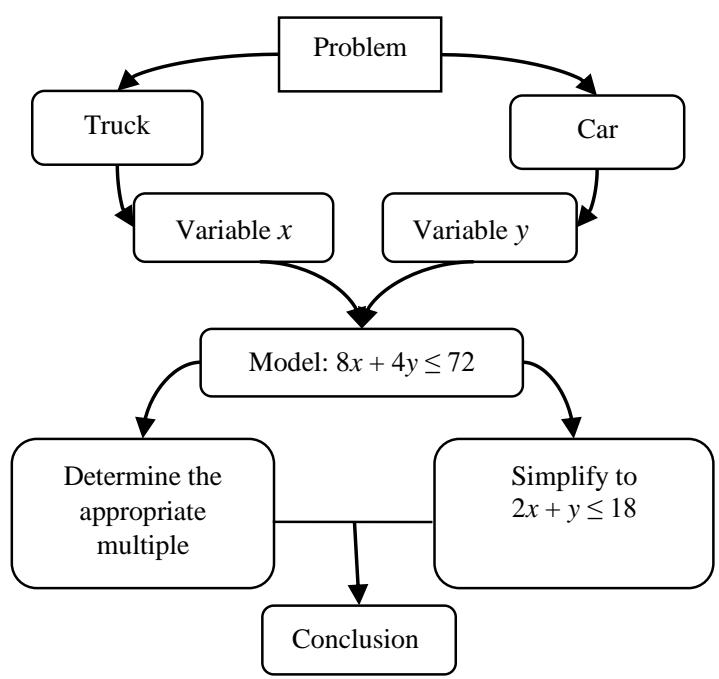

Figure 1 Process for solving math problems

[19] states that the thinking process is a process consisting of receiving information from outside or from within students, processing, inferring and recalling the information from students' memories. Each student will experience a thinking process according to the learning experiences they have participated in, studied and encountered. Some have forgotten, some only remember partly and not completely, some still remember everything well. Students who understand the concepts that have been taught will easily accept the problem-solving questions that will be given. Problem solving problems were given to the three subjects S1, S2 and S3 with the think aloud method and then an in-depth interview was conducted to determine the thinking process and fragmentation that occurred in the problem-solving problem of two-variable linear inequalities.

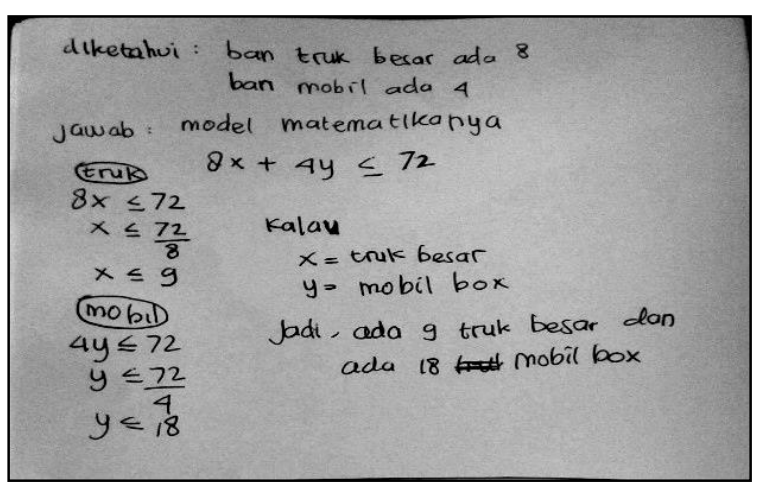

Figure 2 Answers from $\mathrm{S} 1$ in question number 1 


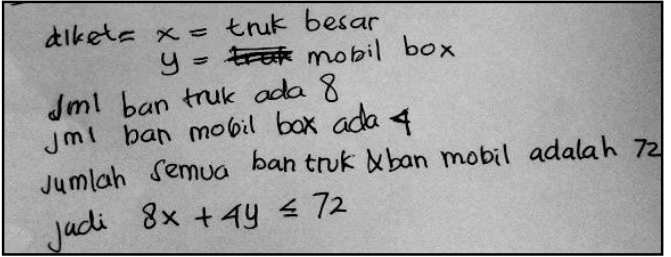

Figure 3 Answers from S3 on question number 1

From the results of working on the questions by the S1 subject (Figure 2), it can be seen that the subject experienced confusion in understanding the questions given, it was seen that the information he received was incomplete. S1 can't remember the concept of inequality, but $\mathrm{S} 1$ is still trying to work on it, digging up information that has been previously learned and in his mind. S1 almost gave up like S3, the subject of S3 could not do it at all because they thought the questions given could not be done because what they knew was lacking and felt unclear (see Figure 3). Interviews were conducted to find out the causes of errors and fragmentation that occurred in S1 and S3.

\begin{tabular}{|c|c|c|}
\hline $\mathrm{R}$ & • & $\begin{array}{l}\text { Do you understand what is asked in the } \\
\text { question? }\end{array}$ \\
\hline $\mathrm{S} 1$ & : & $\begin{array}{l}\text { Yes I understand but I forgot what to do } \\
\text { first if there is a linear inequality of two } \\
\text { variables }\end{array}$ \\
\hline $\mathrm{R}$ & : & $\begin{array}{l}\text { What ideas do you think of when you find } \\
\text { questions like this? }\end{array}$ \\
\hline $\mathrm{S} 1$ & : & $\begin{array}{l}\text { I make an example of } x \text { for big trucks and } \\
y \text { for box cars. I'm trying to enter possible } \\
\text { numbers, for example, if } 8 x=72 \text {, then } \\
x=\frac{72}{8}, x=9 \text {, in the same way } y=18 \\
\text { and then adding up } 9+18 \text { the result is } \\
\text { less than } 72 \text {. }\end{array}$ \\
\hline $\mathrm{R}$ & : & $\begin{array}{l}\text { Why is there an idea to make such a step? } \\
\text { Is there no other way? }\end{array}$ \\
\hline $\mathrm{S} 1$ & . & $\begin{array}{l}\text { It seems that it is correct and when it is } \\
\text { operated, the results are met. }\end{array}$ \\
\hline $\mathrm{R}$ & & $\begin{array}{l}\text { What about the sign of inequality that is } \\
\text { asked in the question? Is it not used to } \\
\text { operate? }\end{array}$ \\
\hline $\mathrm{S} 1$ & 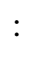 & $\begin{array}{l}\text { I made it into an equation with a "=" sign } \\
\text { so that it can be done. }\end{array}$ \\
\hline
\end{tabular}

Figure 4 Excerpts of an interview with subject 1

From the excerpts of the researcher's interview with S1 (Figure 4), it can be seen that S1 does not fully understand the meaning of the question, writes incorrect information on the question, is still confused about how to do it because there is fragmentation of the thinking structure. The subject immediately got the idea to enter numbers in the equation he had made.
The subject experienced doubts with the answers he wrote down and looked insecure, and afraid of being wrong. Meanwhile, S3 did not seem to solve the questions given well. Researchers conducted interviews with S3. The following is an excerpt from the interview.

\begin{tabular}{|c|c|c|}
\hline $\mathrm{R}$ & & $\begin{array}{l}\text { Why don't you write it down and continue } \\
\text { the work? }\end{array}$ \\
\hline S3 & & $\begin{array}{l}\text { I was only able to get to that Ma'am, I } \\
\text { don't know what else to do, I'm sure the } \\
\text { information in that question is lacking so } \\
\text { the question can't be done }\end{array}$ \\
\hline $\mathrm{R}$ & & why can't it be done? \\
\hline S3 & & $\begin{array}{l}\text { From what I've learned, there are usually } \\
\text { two similarities but I don't understand } \\
\text { either. I only write what is known, then I } \\
\text { try to write down the mathematical model } \\
\text { that fits the given problem. }\end{array}$ \\
\hline $\mathrm{R}$ & & Are you sure this is the only answer? \\
\hline S3 & & $\begin{array}{l}\text { Yes Ma'am, I gave up and didn't know } \\
\text { what else to do. I'm confused how to solve } \\
\text { it. }\end{array}$ \\
\hline $\mathrm{R}$ & & $\begin{array}{l}\text { You didn't try to enter any possible } \\
\text { numbers in order to be able to answer the } \\
\text { questions? }\end{array}$ \\
\hline & & I don't get the answer ma'am \\
\hline
\end{tabular}

Figure 5 Excerpts of interview with subject 3.

Seen from the interview with S3 (Figure 5), he easily gives up and does not want to try things that can be done to solve the problems given. Even after being provoked by the researcher, the subject still doesn't understand how to do it. This is an open question, and the subject is still very unfamiliar with getting the questions as given. Usually, the teacher does not give examples like that, the teacher only gives questions that only exist in books. The following can be seen from S2's answer in solving question number 1 in Figure 6.

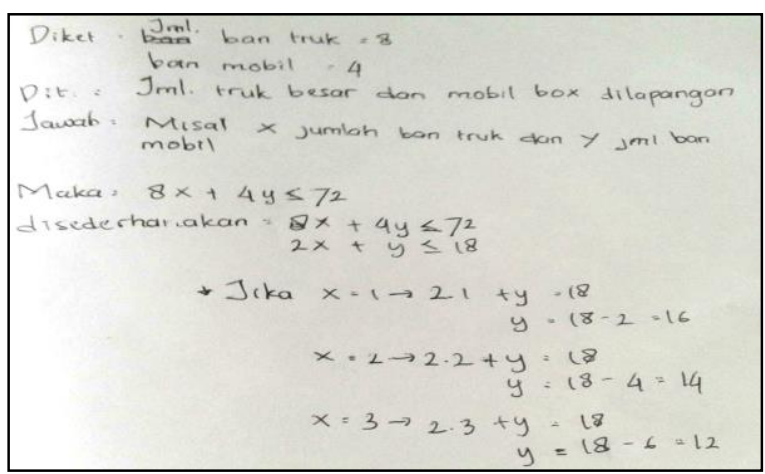

Figure 6 Answers from $\mathrm{S} 2$ in question number 1

Judging from the answers to the results of the work written in S2, S2 was able to understand the 
questions well, in sequence but did not give a conclusion according to what was asked. If not given a conclusion and re-check the answers. There is incomplete information written by on $\mathrm{S} 2$. Here (Figure 7) are the differences in the structure of students' thinking processes on $\mathrm{S} 2$ and $\mathrm{S} 3$.

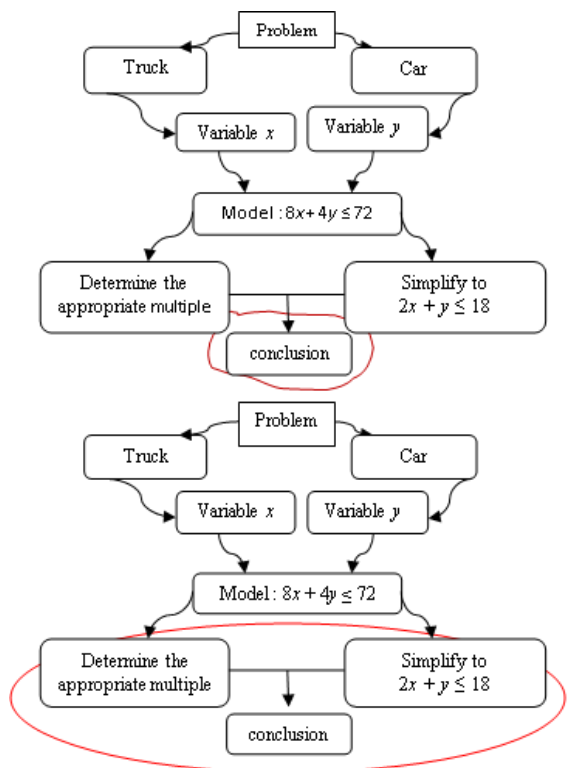

Figure 7 The thinking process of students on the subject of S2 and S3

From what has been obtained from the completion of each student in number 1 , it was found that $\mathrm{S} 1$ could not do it correctly, subject 1 had actually given up and did not work, but after being provoked by the researcher, S1 tried to work so that the questions could be answered, after being traced the S1 actually forgot how to do it if given a linear inequality problem of two variables. S1 said that in the learning process the teacher gave questions only the usual questions and there were no variations, according to the examples so the questions could be done according to the examples that had been given. Another reason stated by $\mathrm{S} 1$ is because distance learning or online makes it impossible to fully understand what is explained by the teacher. The material presented is not obtained in its entirety and is incomplete when it is received by students in receiving information. S1 really could not solve the problem, and seemed to have misunderstood. The error occurred because $\mathrm{S} 1$ experienced fragmentation of the structure of thinking in the category of incomplete structure and unordered structure. When getting material on linear inequalities of two variables, subject 1 did not understand and when asked to work on problem solving problems he had difficulty, no information was understood, causing fatal errors when given a question.
The data obtained on S3 found that S3 could not answer the question at all. S3 only wrote down what was known. When given guidance from the researcher, S3 still could not recall the information he had received while studying the linear inequalities of two variables. From what is understood by S3, equations if you want to find the value of the $\mathrm{x}$ and $\mathrm{y}$ variables, then two equations are needed to be solved. S3 considered that the question could not be done because what he knew was lacking, so S3 did not understand and gave up on working on the given question. Problem-solving questions with the type of open-ended questions are very rarely given in the learning process in the classroom. So, students are only given questions with no significant challenges. Even so, there are still many students who do not understand well the concepts that must be built.

While in S2, S2 has written down what is known and what was asked, and is very confident when answering problem solving questions. S2 still remembers the material on the linear inequalities of two variables, but there is little doubt as to whether this is the correct answer written. In addition, S2 still has not written a conclusion as the final answer to the questions given. In solving a problem, complete information is needed in order to obtain a complete and in accordance with the results requested in the problem so that it will be easy to understand.

Given a question to retrace the structure of thinking in constructing the concept of a linear inequality of two variables. The following (Figure 8) is the flow of the thinking process according to the correct thinking structure according to the steps that can be used to solve mathematical problem-solving problems.

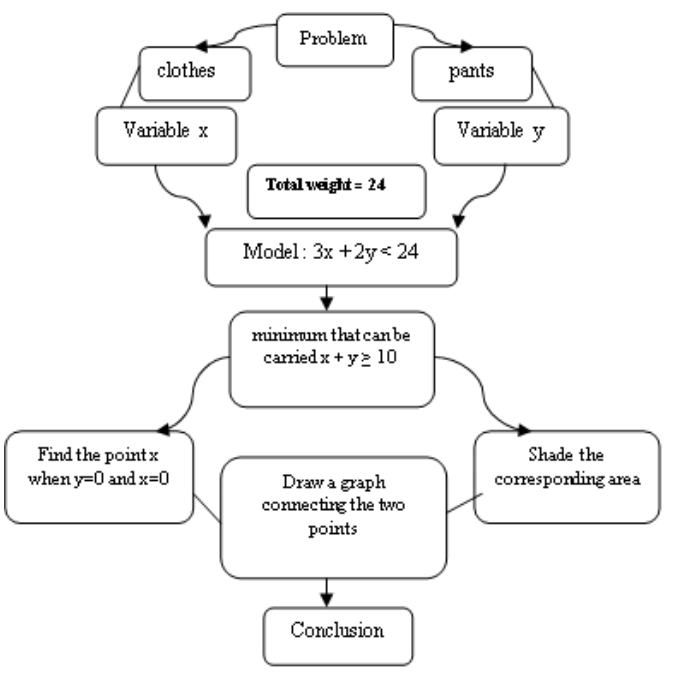

Figure 8 Thinking process in solving math problems 
The following can be seen from S2's answer in solving question number 2 in Figure 9.

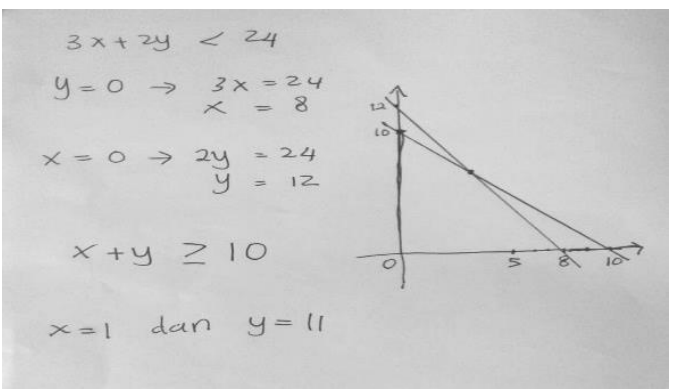

Figure 9 Answers from $\mathrm{S} 2$ in question number 2

Judging from the students' work, S2 has written down what is known but it is still not clear why S2 wrote directly like that. There is no information about what is asked in the question and provides an incomplete answer. The following (Figure 10) is an interview with S2 for question number 2.

\begin{tabular}{|c|c|c|}
\hline $\mathrm{R}$ & : & $\begin{array}{l}\text { what do you understand with the questions } \\
\text { given? }\end{array}$ \\
\hline S2 & $:$ & $\begin{array}{l}\text { I tried to do my best, I immediately made } \\
\text { an example and made a mathematical } \\
\text { model. I'm looking for points } x=0 \text { and } y=0 \\
\text { to graph and get the solution area }\end{array}$ \\
\hline $\mathrm{R}$ & : & Is it true that such a step should be taken? \\
\hline S2 & : & $\begin{array}{l}\text { it seems like that ma'am, I'm also still in } \\
\text { doubt, because I've forgotten a bit }\end{array}$ \\
\hline $\mathrm{R}$ & : & Which part are you still unsure about? \\
\hline S2 & : & $\begin{array}{l}\text { Actually, I still doubt whether it's true, but } \\
\text { what's more doubtful is the part on making } \\
\text { the graph, ma'am, and I still have to read } \\
\text { the example many times }\end{array}$ \\
\hline $\mathrm{R}$ & $:$ & in the graph where is the solution area? \\
\hline $\mathrm{S} 2$ & : & the one at the top, ma'am, as far as I know. \\
\hline $\mathrm{R}$ & . & $\begin{array}{l}\text { which part? So, what is the minimum that } \\
\text { can be transported? Why not write a } \\
\text { conclusion from what is asked by the } \\
\text { question? }\end{array}$ \\
\hline $\mathrm{S} 2$ & $:$ & $\begin{array}{l}\text { oh yeah, I forgot, ma'am, haven't written } \\
\text { and shaded the graph yet. I thought that } \\
\text { my answer was correct. }\end{array}$ \\
\hline
\end{tabular}

Figure 10 Excerpts of an interview with S2

From interviews conducted by researchers and $\mathrm{S} 2$, it can be concluded that $\mathrm{S} 2$ experienced fragmentation of thinking structures. Subject 2 has taken the correct steps but there are steps that have not been carried out, namely writing in full what is known and being asked and writing the conclusion of the completion as requested in the question. Conceptual thinking process: able to express what is known in the problem in their own sentences, able to express in their own sentences in the question, in answering tend to use the concepts that have been studied, and able to mention the elements of the completed concept. When doing problem solving, students are expected to be able to understand about the problem solving given. They have been able to answer questions with the concepts learned. As has been done by S3, he has been able to answer the questions given with the concepts he has learned. S3 in solving problems has been able to apply the concepts that have been learned. Like when working on number 1 .

The results of the think aloud that have been implemented can be concluded on each subject. In this study, it can be seen that $\mathrm{S} 1$ has a construction hole. In working on question number $1, \mathrm{~S} 1$ felt that the answers he wrote were correct with the methods and conclusions he drew. However, that is a wrong concept. There is no way of working on questions like that, from interviews conducted by $\mathrm{S} 1$ giving reasons that have nothing to do with the completion process. It indicates something is missing, and not in the correct order of execution. If you are not given S1 guidance, you will always make mistakes in the next material. In question number 2, S1 also still made the same mistake, $\mathrm{S} 1$ found it difficult to solve it. As in the thought process in S3, S3 in working on problem number 1 could not recall the material on linear inequalities of two variables because during the S3 learning process they could not understand the concept, S3 only remembered that if there was an inequality problem, they were asked to make a graph and then describe the solution area. Meanwhile, in the problem-solving problem given by the researcher, only one equation is known, and that makes S3 confused and feeling hopeless because he doesn't know and can't take steps to solve it. In S2, the thinking process is more complete than in $\mathrm{S} 1$ and $\mathrm{S} 3$, only S2 has fragmentation of pseudo-thinking structures (pseudo construction).

As a teacher, the teacher has a role to find out the errors experienced by students and look for the causes. After knowing it, the teacher tries to find the right solution so that his students do not make mistakes again and carry out the right-thinking process so that they can solve every problem-solving problem given to him. [20] It can be started by reconstructing students' thinking process through developing scaffolding in mathematics learning.

Researchers conducted interviews to determine students' thinking processes in solving mathematical problem-solving problems given. It was found that students' thinking processes have different processes 
according to the understanding of each student in understanding the concepts they have received. As the opinion of Nurman that the mathematical ability of each student affects the problem-solving process carried out. In addition, according to Ruseffendi states that the level of student ability is different related to mathematical concepts, causing differences in students' ability to solve math problems. [21] Thinking mathematically focuses on the role of the emotions in mathematics, particularly in dealing with the high of an 'Aha!' experience which should be enjoyed before subjecting the insight to further scrutiny, and being 'Stuck', requiring a positive approach to analyse what has happened and how this can help to suggest alternative approaches. In order for the structure to think a student can survive in a very long time, it is necessary to also do a treatment to ensure that the way of thinking that is done is correct [22].

\section{CONCLUSION}

The results of this study discuss the fragmentation of students' thinking structures in constructing concepts on the material of linear inequalities of two variables, traced to errors that occur in class XI students. The material for the linear inequality of two variables is found in the material in the previous class, it is hoped that in this study students have received the material and can recall what is in their memory in understanding the material for the linear inequality of two variables. Errors that occur when working on solving math problems are obtained from the answers and interviews. It was found a clear picture of the causes of mathematical problem solving errors, namely the occurrence of fragmentation of thinking structures in constructing concepts in the given problems. This thinking structure fragmentation refers to Subanji's reference, using four types of thinking structure fragmentation, namely pseudo construction, construction holes, randomized structures and incomplete structures. The conclusion from the results of data collection and analysis, it was found that the subject considered the process of solving a linear inequality of two variables the same as the solution for a linear equation, the subject did not write down sequential steps, in the middle of the road when working on the problem had difficulties, doubts and needed to be guided to call back memories he had. Subjects who have forgotten some steps, skip steps that should also be written down, construction holes occur, incomplete structures and unordered structures. In solving problems, each subject experiences differences in solving a problem. This can happen because a person's understanding always experiences a thought process according to what is thought and understood in his memory. But at one time there was an obstacle in the thought process that caused it to be unable to construct concepts to solve mathematical problems.

Designing and building a good learning process that can provide students with an active role and valuable experience in constructing a concept and tracing the fragmentation of the structure of thinking is very much needed if students want to understand the material well. The material for linear inequalities of two variables is considered difficult by some students who have not received previous material information. If you already understand, it will be easier to continue the next material because the mathematics learning material is interconnected continuously.

\section{REFERENCES}

[1] Subanji. (2016). Theory of Defragmentation of Thinking Structures in Constructing Concepts and Solving Mathematical Problems. Malang: UM Press.

[2] Subanji. (2015). Theory of Conceptual Construction Errors and Mathematical Problem Solving. Malang: UM Press

[3] Siswono, T. Y. E. (2002). (Mari wes) Student Thinking Process in Question Submission. National Journal "MATHEMATICS, Journal of Mathematics or Its Learning," 22-25. Retrievedfrom

https://tatagyes.files.wordpress.com/2009/11/pa per02 berikir2.pdf\%0A

[4] Herawati. (1994). Tracing the Ability of Elementary School Students in Understanding Geometric Shapes. (Case Study in grade V SD No. 4 Purus Selatan). Thesis PPs IKIP Malang. Not published.

[5] Subanji, R., \& Supratman, A. M. (2015). The Pseudo-Covariational Reasoning Thought Processes in Constructing Graph Function of Reversible Event Dynamics Based on Assimilation and Accommodation Frameworks. Research in Mathematical Education, 19(1), 6179. http://doi.org/10.7468/jksmed.2015.19.1.61

[6] Supardi, U.S. (2012). The Role of Creative Thinking in the Mathematics Learning Process. Formative Journal, 2(3): 248-262. 
[7] Suherman. (2003). Contemporary Mathematics Learning Strategies. Bandung: UPI.

[8] Hudoyo, H. (1998). Teaching and Learning Mathematics. Jakarta: Director General of Higher Education, Ministry of Education and Culture.

[9] Alfiansyah. M. (2016). Analysis of Students' Reflective Thinking Process in Solving Nonroutine Problems on SPTLDV Material. Makassar: Makassar State University.

[10] Luneta, K., \& Makonye, P. J. (2010). Learner Errors and Misconceptions in Elementary Analysis: A Case Study of a Grade 12 Class in South Africa. Acta Didactica Napocensia, 3(3), 35-45. Retrieved from https://files.eric.ed.gov/fulltext/EJ1056125.pdf

[11] Young, R and O'Shea, T. (1981). Errors in Children's Subtraction. Cognitive Science. 5 (2): $152-177$

[12] Polya, G. (1973). Reviewed Work: How to Solve It A New Aspect of Mathematical Method. The Mathematical Gazette, 30, 181. Retrieved from http://www.jstor.org/stable/3609122?origin=cro $\underline{\text { ssref }}$

[13] Kusumaningrum, M., \& Saefudin, A. A. (2012). Optimizing Mathematical Thinking Ability through Mathematical Problem Solving. Proceedings of the Contribution of Mathematics and Mathematics Education in Building the Character of Teachers and Students, (November), 978-979.

[14] Subanji, R., \& Supratman, A. M. (2015). The Pseudo-Covariational Reasoning Thought Processes in Constructing Graph Function of Reversible Event Dynamics Based on Assimilation and Accommodation Frameworks. Research in Mathematical Education, 19(1), 6179. http://doi.org/10.7468/jksmed.2015.19.1.61

[15] Muslim, R. I., Usodo, B., \& Pratiwi, H. (2021). Pseudo Thinking Process in Understanding the Concept of Exponential Equations. In IOP Conference Series: Earth and Environmental Science (Vol. 1808). http://doi.org/10.1088/1742$\underline{6596 / 1808 / 1 / 012043}$

[16] Ruseffendi. (2010). Teaching Mathematics to Improve CBSA. Bandung: Tarsito.
[17] Sutama. (2010). Educational Research Methods. First print. Surakarta: Fairuz. Media.

[18] Meolong, L. J. (2006). Qualitative Research Methodology. Bandung: Rosdakarya Teenagers

[19] Zuhri, D. 1998. The Thinking Process of Class II Students at SMP NEGERI 2016 PEKANBARU in Solving Comparison of Values and Comparison of Values. Unpublished Thesis : UNESA

[20] Afriyani, D., Sa'Dijah, C., Subanji, S., \& Muksar, M. (2019). Students' construction error in translation among mathematical representations. In Journal of Physics: Conference Series (Vol. 1157). $\quad$ http://doi.org/10.1088/1742$\underline{6596 / 1157 / 3 / 032098}$

[21] Tall. (2009). The Development Of Mathematical Thinking: Problem-Solving And Proof

[22] Wibawa, K. A., Nusantara, T., Subanji, S., \& Parta, I. N. (2017). Fragmentation of Thinking Structure's Students to Solving the Problem of Application Definite Integral in Area. International Education Studies, 10(5), 48. http://doi.org/10.5539/ies.v10n5p48 